\title{
Réflexions sur l'autoréflexivité balzacienne. Textes réunis et présentés par Andrew Oliver et Stéphane Vachon
}

\section{Marco Stupazzoni}

\section{(2) OpenEdition}

1 Journals

\section{Edizione digitale}

URL: https://journals.openedition.org/studifrancesi/40912

DOI: $10.4000 /$ studifrancesi.40912

ISSN: 2421-5856

\section{Editore}

Rosenberg \& Sellier

\section{Edizione cartacea}

Data di pubblicazione: 1 juillet 2004

Paginazione: 208-209

ISSN: 0039-2944

\section{Notizia bibliografica digitale}

Marco Stupazzoni, «Réflexions sur l'autoréflexivité balzacienne. Textes réunis et présentés par Andrew Oliver et Stéphane Vachon», Studi Francesi [Online], 142 (XLVIII | I) | 2004, online dal 30 novembre 2015, consultato il 09 septembre 2021. URL: http://journals.openedition.org/studifrancesi/40912 ; DOI: https://doi.org/10.4000/studifrancesi.40912

Questo documento è stato generato automaticamente il 9 septembre 2021.

\section{cc) (†) $\odot$}

Studi Francesi è distribuita con Licenza Creative Commons Attribuzione - Non commerciale - Non opere derivate 4.0 Internazionale. 


\title{
Réflexions sur l'autoréflexivité balzacienne. Textes réunis et présentés par Andrew Oliver et Stéphane Vachon
}

\author{
Marco Stupazzoni
}

\section{NOTIZIA}

AA. VV., Réflexions sur l'autoréflexivité balzacienne. Textes réunis et présentés par Andrew OLIVER et Stéphane VACHON, Toronto, Centre d'études du XIX ${ }^{\mathrm{e}}$ siècle Joseph Sablé, 2002, pp. 196.

$1 \quad S / Z$ di Roland Barthes ha rappresentato una svolta cruciale nell'investigazione formale dell'opera di Balzac e nella legittimazione di una scrittura narrativa, quella di Balzac appunto, la cui modernità risiede nella reversibilità e nella pluralità del testo. Ricontestualizzare lo scrittore nel proprio tempo e all'interno dei ritmi specifici della sua creazione letteraria significa «réinstaller Balzac au coeur de la modernité» (Andrew OLIVER, Stéphane VACHON, Réflexions sur l'autoréflexivité balzacienne: présentation, p. 6) e riconsiderare, nella sua variegata organicità, la specificità della sua prosa.

Gli studî riuniti in questo volume, che raccoglie gli atti di due 'colloques': Intertextualités balzaciennes et Nouveaux Mondes balzaciens, svoltisi a Toronto e a Parigi tra l'ottobre 1999 e il maggio 2000, assumono come oggetto particolare di indagine le «manifestations réflexives de la prose balzacienne» e le «formes qu'elle donne à son travail sur ellemême» (p. 8).

3 La prima parte (Seuils) considera il paratesto balzachiano come un insieme di discorsi solo apparentemente esterni alle dinamiche narrative (Roland LE HUENEN, Balzac et le discours préfaciel, pp. 15-25); a questo proposito, Rachel SAUVÉ (Au delà de l'édification. Tracé de quelques leitmotive dans un siècle de notices sur «La Comédie humaine», pp. 27-38) 
analizza lo spazio discorsivo della critica letteraria su Balzac, alla luce delle diverse forme di «discours préfaciel» che, da G. Sand a P.-G. Castex, hanno attraversato in vario modo le edizioni della Comédie humaine.

4 La seconda parte (Histoire et société) si apre con l'intervento di Émeline DHOMMÉ («Melmoth reconcilié» ou un diable peut en cacher un autre, pp. 41-54), in cui l'A. studia la duplicità diabolica della scrittura romanzesca balzachiana in relazione alla rappresentazione di una modernità urbana instabile e fluttuante sotto il segno del denaro.

Graham FALCONER (Balzac historien des mentalités? Lecture de "César Bitotteau», pp. 55-65) ritiene che il valore storico della Comédie humaine, e in particolare di César Birotteau, «repose moins sur sa vérité objective /.../ que sur une vérité subjective, un 'comment c'était réellement' intérieur, à la fois psychologique et collectif» (p. 55).

Marie-Christine AUBIN (Balzac et l'illusionnisme social, pp. 67-79) mostra che la rappresentazione sociale dei personaggi si esprime, in Balzac, «par leur habitus et que les actions visant à la réussite sociale sont motivées d'une part par la volonté de distinction du personnage et d'autre part par l'intérêt» (p. 68).

7 Lo studio di Aline Mura («Adolphe», un livre «abymé» dans deux romans de Balzac, pp. 83-96) inaugura la terza parte intitolata Formes et techniques. L'A. esamina le forme e le tecniche messe in gioco, in Béatrix e ne La Muse du département, nel discorso intertestuale balzachiano, all'interno del quale Adolphe «ne saurait seulement tenir lieu /.../ de palimpseste puisque le texte balzacien, protéiforme et subversif, réécrit de fait les pages noircies dont les signes ne sont pas effacés et, partant, induit une lecture de l'entre-deux, des interstices et des silences» (p. 83).

8 Gabriel moyal (La faim de l'histoire. «Le cousin Pons, Le Constitutionnel» et la politique de la cuisine, pp. 97-118) offre un'interessante riflessione critica sui 'tansferts' discorsivi tra stampa politica e romanzo, con un riferimento particolare a Le cousin Pons, pubblicato in forma di »feuilleton» nei giornali.

9 Paul PERRON (Du pseudonyme à la signature. Le quotidien chez Balzac, pp. 119-130) prende in esame il tema del quotidiano in Balzac dalle prime 'œuvres de jeunesse' fino alla Maison di chat-qui-pelote. Si tratta, per l'A., non solo di sondare le molteplici dimensioni del quotidiano nei suoi rapporti con la finzione letteraria, ma, allo stesso tempo, di «confronter certaines pratiques du roman du pseudonyme avec celles du récit de la signature; celles de l'anonymat avec celles de la reconnaissance» (p. 119).

La quarta ed ultima sezione (Genres) presenta i seguenti contributi: Michael Tilby (Roman du secret, secret du roman. La leçon du «Dernier Chouan», pp. 133-153) indaga sul modello parodistico sterniano all'interno delle strutture del romanzo storico 'alla $\mathrm{W}$. Scott'.

11 Andrew OLIVER ((Im)Modeste Mignon. Un roman balzacien en déshabillé, pp. 155-167) osserva che, in Modeste Mgnon, Balzac «fournit une espèce de mise en scène de l'écriture qui abolit d'une certaine manière les frontières non seulement entre les différents genres littéraires, mais aussi celles entre la littérature et d'autres formes artistiques» (p. 158).

Dominique LAPORTE (Honoré de Balzac romancier-essayiste. Pour une approche de intergénéricité balzacienne, pp. 169-179) sottolinea la «relativisation» messa in atto nell'Avant-propos e, a proposito di Honorine, «l'argumentation, qui s'apparente, à maints égards, à la dynamique de l'écriture essayiste; et le style, qui exemplifie par endroits 
un trait formel de l'essai: la récurrence d'éléments phonétiques, lexicaux, syntaxiques ou sémantiques» (p. 171).

13 Scott LEE (Retour à Tours. «Les Contes drolatiques» ou la lettre des origines, pp. 181-188) valuta gli effetti della lettura dei Contes e dei loro paratesti (prologhi e commenti nella corrispondenza) in relazione allo statuto del loro spazio originario (Tours) non solo «en tant qu'espace réel ayant inspiré le décor de la plupart des Contes drolatiques, mais également et plutôt en tant que signifiant» (p. 182). 